\title{
EXTRAÇÃo gUímiCA E ENZIMÁticA DAS PROTEÍNAS DO FUBÁ DE MILHO ${ }^{1}$
}

\author{
Michely CAPOBIANGO ${ }^{2}$, Claudia Regina VIEIRA ${ }^{2}$, Ana Luiza SANTIAGO E SILVA ${ }^{2}$, \\ José Virgílio COELHO ${ }^{2}$, Sérgio Duarte SEGALL ${ }^{3}$, Marialice Pinto Coelho SILVESTRE ${ }^{2, *}$
}

\begin{abstract}
RESUMO
Diferentes métodos químicos e um enzimático foram testados para extração das proteínas do fubá de milho. A avaliação do rendimento da extração protéica foi feita pela determinação do teor de proteína e de sólidos totais dos resíduos obtidos. Para a extração química das proteínas, uma solução alcalina, isoladamente ou em associação com etanol, foi empregada como solvente. O método alcalinoalcoólico seqüencial foi o mais eficiente, dentre os métodos químicos testados, tendo alcançado $88,2 \%$ de rendimento. Por outro lado, o método alcalino (75,5\% de rendimento) apresenta a vantagem de não empregar etanol, reduzindo os custos do processo, pois se evita a etapa de remoção desse solvente. Para a extração enzimática, foi utilizada uma protease de Bacillus liccheniformis. As variáveis, tempo e temperatura, empregadas no método enzimático influenciaram no rendimento da extração protéica do fubá de milho. Os melhores resultados foram obtidos em 5,15 e $24 \mathrm{~h}$ a $55^{\circ} \mathrm{C}$, que não apresentaram diferença significativa, sendo que a condição mais vantajosa do ponto de vista econômico foi a de $5 \mathrm{~h}$ a $55^{\circ} \mathrm{C}$ com um rendimento de $83,8 \%$.

Palavras-chave: cereal, derivado de milho, extração protéica, rendimento de extração.
\end{abstract}

\section{SUMMARY}

CHEMICAL AND ENZYMATIC EXTRACTIONS OF PROTEINS FROM BRAZILIAN CORN FLOUR. Different chemical methods and an enzymatic one were tested for protein extraction from Brazilian corn flour. The protein extraction yield was calculated using the values of protein and solid contents of the residues. For the chemical extraction, an alkaline solution, separately or in association with ethanol, was used as a solvent. The sequential alkaline-alcoholic method was the most efficient, having reached a yield of $88.2 \%$. However, the alkaline method presents the advantage of not using ethanol, reducing the risks for health, as well as decreasing the costs of the process. For the enzymatic extraction, a protease of Bacillus liccheniformis was used. The time and the temperature used in this method influenced the extraction yield. The best results were obtained for 5,15 and 24 hours at $55^{\circ} \mathrm{C}$, and the most advantageous condition from the economical point of view, was that one obtained for 5 hours at $55^{\circ} \mathrm{C}$, having reached a yield of $83.8 \%$.

Keywords: brazilian corn flour, protein extraction, extraction yield.

\section{1 - INTRODUÇÃO}

O milho, juntamente com o arroz e o trigo, é um dos mais importantes grãos de cereais no mundo, fornecendo nutrientes para seres humanos e animais e servindo como material básico à produção de amido, óleo e proteína, bebidas alcoólicas, adoçantes e, mais recentemente, como combustível [12].

Além disso, o milho é o cereal mais produtivo dentre os três grãos, com uma média mundial, durante os últimos três anos, de 4,3 toneladas/hectare, em comparação a 2,7 e 3,8 toneladas/hectare de trigo e arroz, respectivamente [9]. O consumo per capita de milho no Brasil foi de $21,0 \mathrm{~kg} / \mathrm{ha}-$ bitante no ano de 2002, fornecendo cerca de $180 \mathrm{Kcal} /$ dia e 4,0 g proteína/dia por habitante [11].

O conteúdo de proteínas em diferentes tipos de milho varia entre 6 e $12 \%$ na base seca, sendo que aproximadamente $75 \%$ destes componentes estão contidos no endosperma [11].

\footnotetext{
${ }^{1}$ Recebido para publicação em 27/3/2006. Aceito para publicação em 20/10/2006 (001705)

${ }^{2}$ Departamento de Alimentos, Faculdade de Farmácia,

Universidade de Minas Gerais (UFMG),

Av. Antônio Carlos, 6627, sala 3070-B3,

CEP 31270-901, Belo Horizonte (MG), Brasil

E-mail:malice@farmacia.ufmg.br

${ }^{3}$ Departamento de Ciências Biológicas e Saúde, Faculdade de Nutrição, Centro Universitário de Belo Horizonte (UniBH),

* A quem a correspondência deve ser enviada
}

As proteínas do grão de milho podem ser classificadas em seis frações, de acordo com LANDRY \& MOUREAUX [20], como albumina, globulina, zeína, glutelina 1 , glutelina 2 e glutelina 3 . A zeína é uma prolamina, que ocorre especificamente em cereais, e é a maior classe das proteínas constituintes do milho, correspondendo a aproximadamente $45-50 \%$ do total.

Diferentes procedimentos, utilizando solventes, para extrair as proteínas dos cereais são relatados na literatura, nos quais fatores como concentração e tipo de solvente, temperatura e tempo da extração variam com o intuito de aumentar a eficiência do processo $[6,7,10,18,19,20,21$, $23,25,29,33$ ]. O método usado para isolar as proteínas tem efeitos importantes nas suas propriedades [1]. O tratamento alcalino das proteínas pode provocar a sua desnaturação pela desestabilização das estruturas terciárias e facilitar sua solubilização. Por outro lado, o pH alcalino pode aumentar as chances de racemização dos aminoácidos e sua destruição, levando à formação de novos compostos que poderiam alterar as propriedades nutricionais e funcionais das proteínas [27].

$\mathrm{Na}$ maioria dos trabalhos sobre a extração química das proteínas de cereais, etanol e solução de hidróxido de sódio são empregados como solventes em concentrações variadas $[10,20,21,23,25,33]$. Geralmente, no milho, a fração protéica solúvel em etanol é maior do que a fração solúvel em álcali, e ambas constituem 80-90\% da proteína do milho [19]. 
Não foram encontrados na literatura trabalhos abordando a extração enzimática de proteínas do milho e derivados. Estudos foram realizados com outros alimentos, tais como arroz e soja, no qual o interesse dos autores estava voltado para a separação das proteínas destes alimentos [8, 13, 30]. Em outros casos, a utilização deste método estava associada à separação do amido [1,32].

Várias enzimas têm sido utilizadas na extração enzimática de proteínas. Entre estas, encontram-se a pancreatina, as proteases alcalina, fúngica ou bacteriana [8]; uma endoprotease (alcalase de grau alimentício do Bacillus liccheniformis); um complexo de proteases (flavourzima do Aspergillus oryzae) seguido de uma preparação de carboidrase do Aspergillus aculeatus e do Humicola insolens [13]; endoprotease e amilase [30]; $\alpha$-amilase (BAN 240 L) e protease (Promozyme 400 L) [1].

Visando a utilização do fubá de milho como matéria-prima para a produção de suplementos nutricionais diversos, este trabalho envolveu a determinação da composição química e a otimização da extração protéica, por diversos métodos químicos e um enzimático. Neste caso, a enzima empregada consistiu de uma protease de Bacillus liccheniformis.

\section{2 - MATERIAL E MÉTODOS}

\section{1 - Material}

O fubá de milho foi adquirido no comércio de Belo Horizonte, MG. A enzima Protemax 580 L foi cedida pela Prozyn (São Paulo, Brasil). O "Kit” para determinação de fibra alimentar total, TDF-100A, foi adquirido da Sigma Chemical Co. (St. Louis, MO, USA). Os demais reagentes foram de grau analítico.

\section{2 - Métodos}

\subsection{1 - Determinação da composição centesimal do fubá de milho}

A composição centesimal do fubá de milho foi determinada segundo os métodos descritos na AOAC [2]. A umidade foi determinada pelo método de secagem em estufa ventilada (Quimis Q-314M242, série 020, Diadema, SP) a $105{ }^{\circ} \mathrm{C}$ até peso constante; as cinzas ou minerais, por incineração, em mufla a $550{ }^{\circ} \mathrm{C}$; os lípides, por extração com éter etílico, Soxhlet modificado (Quimis Q-308G26, série 018, Diadema, SP); as proteínas foram determinadas pelo método de micro-kjeldahl; as fibras alimentares, pelo método enzimático; os carboidratos, por diferença. $\mathrm{O}$ fator de conversão de nitrogênio para proteína usado foi 5,65, específico para milho [24].

\subsection{2 - Extração das proteínas do fubá de milho}

\subsubsection{1 - Extração química}

Para a extração química das proteínas, foi empregada uma solução alcalina, isoladamente ou em associação com o etanol, tendo sido utilizadas algumas variações. No primeiro caso, cujo procedimento está descrito a seguir, foi utilizado o método alcalino, descrito por CONNOR, SAUNDERS \& KOHLER [5], e modificado por BIZZOTTO et al. [3] quanto ao pH, tempo de agitação e método de separação do resíduo.

A $10 \mathrm{~g}$ da amostra foram adicionados $50 \mathrm{~mL}$ de água destilada e o pH ajustado para 12 com uma solução de $\mathrm{NaOH}$ a $3 \mathrm{~mol} / \mathrm{L}$. Agitou-se em agitador magnético (Fisatom, São Paulo, Brasil), por $1 \mathrm{~h}$. Centrifugou-se a 957 x g, por $10 \mathrm{~min}$, a $25{ }^{\circ} \mathrm{C}$ (Centrífuga Jouan, BR 4i, Saint Herblain, França). Separou-se o sobrenadante e o resíduo foi lavado uma vez com $10 \mathrm{~mL}$ de $\mathrm{NaOH}$ a $0,1 \mathrm{~mol} / \mathrm{L}$ e, em seguida, duas vezes com $10 \mathrm{~mL}$ de água destilada, tendo sido centrifugado, nas mesmas condições citadas acima, após cada lavagem. O resíduo foi, então, pesado e submetido às determinações dos teores de proteína e de sólidos totais [2].

Testou-se, em seguida, uma modificação do método alcalino, aqui denominado de alcalino-alcalino. Nesse caso, a partir do resíduo obtido no método alcalino repetiu-se o mesmo procedimento de extração protéica.

Para a associação da solução alcalina com o etanol, seguiu-se, inicialmente, o método descrito por KAMPEN [19], aqui denominado de alcalino-alcoólico simultâneo. Este método se assemelha ao alcalino, sendo que, além dos $50 \mathrm{~mL}$ de água destilada adicionados à amostra, 40 mL de uma solução etanólica a $70 \%(\mathrm{v} / \mathrm{v})$ foram adicionados, juntamente com um volume de solução de $\mathrm{NaOH}$ a $3 \mathrm{~mol} / \mathrm{L}$, suficiente para atingir o $\mathrm{pH} 12,0$.

Em seguida, foram testadas três modificações do método de KAMPEN [19]. Na primeira, aqui designada de método alcalino-alcoólico seqüencial, adicionaram-se $40 \mathrm{~mL}$ de solução etanólica a $70 \%$ (v/v) ao resíduo, obtido como descrito para o método alcalino, e repetiram-se as etapas de centrifugação e lavagem, neste caso, apenas com água destilada. Na segunda modificação, aqui denominada método alcoólico-alcalino seqüencial, seguiu-se o mesmo procedimento do método alcalino-alcoólico seqüencial, tendo sido alterada apenas a ordem de adição dos solventes. $\mathrm{Na}$ terceira modificação, aqui denominada de método alcalinoalcoólico com ajuste de $\mathrm{pH}$, ajustou-se o $\mathrm{pH}$ de 12,0 para 7,0 do primeiro resíduo obtido pelo método alcalino-alcoólico seqüencial, após a extração alcalina, com ácido clorídrico a $3 \mathrm{~mol} / \mathrm{L}$. Logo após, realizou-se a segunda extração com solução etanólica a $70 \%$ (v/v), como descrito para o método alcalino-alcoólico.

\subsubsection{2 - Extração enzimática}

A extração enzimática foi baseada no método descrito por WANG \& WANG [32], sendo que alguns parâmetros, tais como proporção de água inicial, $\mathrm{pH}$, tempo de centrifugação e relação E:S, foram modificados com o objetivo de aumentar o rendimento do processo.

A amostra de fubá de milho foi inicialmente passada em peneira de 50 "mesh". Em seguida foi suspensa em água, na proporção de 1:5 (p/v) e agitada no ultratur- 
rax (IKA Labortechnix, T25 basic, Wilmington, EUA) a $19.000 \mathrm{rpm}$ por $5 \mathrm{~min}$. Após ajuste do $\mathrm{pH}$ para 9,5, com solução de $\mathrm{NaOH}$ a $3 \mathrm{~mol} / \mathrm{L}$, levou-se ao banho de óleo a $55{ }^{\circ} \mathrm{C}$ ou $60{ }^{\circ} \mathrm{C}$. A enzima Protemax $580 \mathrm{~L}$ foi adicionada na relação enzima:substrato $(\mathrm{E}: \mathrm{S})$ de 1:10 e a hidrólise foi realizada em diferentes tempos (Tabela 1). Em seguida, centrifugou-se a $1700 \times$ g por $15 \mathrm{~min}$, a $25{ }^{\circ} \mathrm{C}$. Separou-se o sobrenadante e o resíduo foi lavado duas vezes com água destilada, tendo sido centrifugado nas mesmas condições citadas anteriormente, após cada lavagem. O resíduo foi pesado e submetido às determinações dos teores de proteína e sólidos totais [2].

TABELA 1 - Parâmetros utilizados na extração enzimática das proteínas do fubá de milho.

\begin{tabular}{ccc}
\hline Amostras & Temperatura $\left({ }^{\circ} \mathbf{C}\right)$ & Tempo (h) \\
\hline EPF 1 & 55 & 1 \\
EPF 2 & 55 & 5 \\
EPF 3 & 55 & 15 \\
EPF 4 & 55 & 24 \\
EPF 5 & 60 & 1 \\
EPF 6 & 60 & 5 \\
\hline
\end{tabular}

$\mathrm{EPF}=$ Extrato protéico do fubá de milho.

\subsubsection{3 - Determinação do rendimento da extração protéica}

O rendimento da extração protéica foi determinado indiretamente, empregando-se o teor de proteínas do resíduo. Para tal, empregou-se a Equação 1:

$R(\%)=100-$

[proteína no resíduo x peso do resíduo x 100$]$

sendo:

Proteína no resíduo $=$ teor de proteína no resíduo, obtido após a extração das proteínas do fubá de milho, em g/100 g; b.s.;

Peso do resíduo $=$ quantidade do resíduo obtido após a extração, b.s. (g);

Proteína da amostra = teor de proteína no fubá de milho, em g/100 g; b.s.; e

Peso da amostra = quantidade de fubá de milho utilizada na extração, (g).

\section{3 - Análise estatística}

Todos os experimentos foram feitos com três repetições e as análises realizadas em triplicata. Utilizou-se a Análise de Variância (ANOVA fator único) e o Teste de Duncan a 5\% de probabilidade, para comparar o rendimento de extração das proteínas do fubá de milho [26].

\section{3 - RESULTADOS E DISCUSSÃO}

\section{1 - Composição centesimal do fubá de milho}

Encontram-se, na Tabela 2, os resultados obtidos para os teores dos componentes do fubá de milho. De uma maneira geral, os valores encontrados no presente trabalho estão próximos dos citados na literatura. As diferenças observadas estão associadas aos teores de fibra alimentar, cujo valor obtido foi cerca de duas vezes maior que os da marca Hikari [31] e aos do fubá cru sem marca [31]. Além disso, comparando-se com os dados da tabela de composição de alimentos de FRANCO [14], o teor de umidade aqui encontrado foi inferior, enquanto que os de cinzas totais e de carboidratos foram superiores, sendo que para as cinzas a diferença foi cerca de três vezes maior. Esta variação na composição química de um alimento pode estar relacionada às condições de cultivo, clima, solo e adubação. Além disso, GONÇALVES et al. [15] relatam que o teor de proteína pode ser influenciado pelo grau de germinação do grão de milho. Os métodos empregados na determinação de fibra também podem influenciar nos resultados obtidos, embora não tenham sido mencionados na literatura consultada.

TABELA 2 - Composição centesimal do fubá de milho.

\begin{tabular}{lcccc}
\hline & \multicolumn{4}{c}{ Teores (g/100 g) } \\
\cline { 2 - 5 } Componentes & Valores obtidos $^{\mathbf{1}}$ & USP $^{\mathbf{2}}$ & USP $^{\mathbf{3}}$ & FRANCO $^{4}$ \\
\hline Umidade & $11,04 \pm 0,04$ & 12,40 & 9,88 & 16,42 \\
Proteína & $6,13 \pm 0,20$ & 5,70 & 6,90 & 7,80 \\
Lípides & $1,94 \pm 0,18$ & 2,20 & 2,16 & 2,20 \\
Cinzas totais & $0,48 \pm 0,03$ & 0,50 & 0,50 & 0,18 \\
Fibra alimentar & $5,86 \pm 0,08$ & 2,80 & 4,04 & - \\
total & & & & \\
Carboidratos & 80,42 & 79,20 & 80,56 & 73,40 \\
\hline
\end{tabular}

${ }^{1}$ Valores obtidos no presente trabalho com o desvio padrão; ${ }^{2}$ [31], Fubá de milho da Hikar Indústria e Comércio Ltda; $\mathrm{e}^{3}[31]$, Fubá de milho, sem marca. ${ }^{4}[14]$.

\section{2 - Eficiência da extração química das proteínas}

Na Tabela 3, estão apresentados os resultados obtidos para o rendimento da extração química das proteínas do fubá de milho, empregando-se os diferentes métodos.

TABELA 3 - Teor de proteínas no resíduo e rendimento da extração química das proteínas do fubá de milho, com diferentes métodos de extração.

\begin{tabular}{lcc}
\hline Métodos de extração & $\begin{array}{c}\text { Teor de proteína } \\
\text { no resíduo (\%) }\end{array}$ & $\begin{array}{c}\text { Rendimento de } \\
\text { extração (\%) }\end{array}$ \\
\hline Alcalino & $1,79^{\mathrm{bc}}$ & $75,5^{\mathrm{bc}}$ \\
Alcalino-alcalino seqüencial & $2,10^{\mathrm{ab}}$ & $72,9^{\mathrm{cd}}$ \\
Alcalino-alcoólico simultâneo & $1,73^{\mathrm{bc}}$ & $75,7^{\mathrm{bc}}$ \\
Alcalino-alcoólico seqüencial & $0,95^{\mathrm{d}}$ & $88,2^{\mathrm{a}}$ \\
Alcoólico-alcalino seqüencial & $1,72^{\mathrm{c}}$ & $77,5^{\mathrm{b}}$ \\
Alcalino-alcoólico com ajuste & $2,27^{\mathrm{a}}$ & $70,6^{\mathrm{d}}$ \\
de pH & &
\end{tabular}

Os resultados representam médias de triplicatas. Médias indicadas por letras iguais não diferem entre si a $5 \%$ de probabilidade pelo teste de Duncan. 
Como pode ser observado, o maior rendimento da extração foi alcançado pelo método alcalino-alcoólico seqüencial (88,2\%), uma vez que o emprego de uma solução alcalina, seguido de uma solução alcoólica a 70,0\%, mostrou ser mais eficaz para aumentar a solubilidade das proteínas e, conseqüentemente, a porcentagem de rendimento de extração dos métodos testados. KAMPEN [19] relata que o uso de solventes, de forma seqüencial, na extração protéica, pode aumentar o rendimento para alguns tipos de matéria-prima, especificamente para cereais.

Além disso, os resultados aqui obtidos estão de acordo com o esperado teoricamente, ou seja, a maior parte da fração protéica do milho é solúvel em etanol e álcali, sendo facilmente extraída por estes solventes [19].

Apesar do método alcalino ter apresentado menor rendimento do que o alcalino-alcóolico seqüencial, o emprego de apenas um solvente e a eliminação da etapa de remoção de álcool o torna mais econômico.

Não foram encontrados na literatura, dados sobre o rendimento de extração protéica do fubá de milho. Os poucos trabalhos encontrados referem-se ao grão de milho e, em apenas um, o rendimento da extração protéica foi superior ao obtido neste trabalho. Assim, KAMPEN [19] conseguiu extrair $82 \%$ das proteínas, empregando o método alcalino-alcoólico simultâneo, enquanto que, no presente trabalho, este mesmo método apresentou um rendimento de aproximadamente $76 \%$.

Por outro lado, HOJILLA-EVANGELISTA, JOHNSON \& MYERS [18] relataram um rendimento de apenas 57\% ao utilizar o método alcalino-alcoólico simultâneo, bem inferior ao valor encontrado no atual trabalho (76\%).

Dois outros autores utilizaram métodos diferentes aos aqui empregados, e os seus rendimentos de extração foram inferiores. Assim, SHUKLA, CHERYAN \& DE VOR [29] obtiveram uma média de 50,6\% no rendimento de extração das proteínas do grão de milho, utilizando somente uma solução alcoólica a 70\%. LANDRY [20] recuperou $63,4 \%$ do total de proteínas do grão de milho, empregando extração por fracionamento pelo emprego de solventes variados $(\mathrm{NaCl}$ a $0,5 \mathrm{~mol} / \mathrm{L}$, etanol a $60 \%$, 2-mercaptoetanol, tampão borato a 0,0152 mol/L, pH 10 e sulfato dodecil de sódio a $0,5 \%$ ).

Para o teor de proteína no resíduo após a extração protéica, apenas um relato foi encontrado na literatura [32]. Neste caso, a matéria-prima utilizada foi o arroz, tendo sido empregado o método alcalino e o resultado foi de $0,12 \%$, inferior ao valor de $1,79 \%$ obtido para o mesmo método aqui empregado.

\section{3 - Eficiência da extração enzimática das proteínas}

Na Tabela 4, são apresentados os resultados do rendimento da extração enzimática das proteínas do fubá de milho encontrados no presente trabalho. Como se pode observar, os melhores resultados foram obtidos a $55{ }^{\circ} \mathrm{C}$, com 5 h (EPF 2), 15 h (EPF 3) e 24 h de extração (EPF 4), tendo atingido o valor médio de $85,3 \%$. Por outro lado, para a amostra EPF 1, obteve-se o menor rendimento de extração $(71,5 \%)$.

TABELA 4 - Teor de proteínas no resíduo e rendimento da extração enzimática das proteínas do fubá de milho

\begin{tabular}{ccc}
\hline $\begin{array}{c}\text { Amostras e parâmetros } \\
\text { da extração }\end{array}$ & $\begin{array}{c}\text { Teor de proteínas no } \\
\text { resíduo (\%) }\end{array}$ & $\begin{array}{c}\text { Rendimento de } \\
\text { Extração (\%) }\end{array}$ \\
\hline EPF $1\left(55^{\circ} \mathrm{C}, 1 \mathrm{~h}\right)$ & $2,3^{\mathrm{a}}$ & $71,5^{\mathrm{d}}$ \\
$\operatorname{EPF} 2\left(55^{\circ} \mathrm{C}, 5 \mathrm{~h}\right)$ & $1,4^{\mathrm{d}}$ & $83,8^{\mathrm{a}}$ \\
$\operatorname{EPF} 3\left(55^{\circ} \mathrm{C}, 15 \mathrm{~h}\right)$ & $1,3^{\mathrm{d}}$ & $85,4^{\mathrm{a}}$ \\
EPF $4\left(55^{\circ} \mathrm{C}, 24 \mathrm{~h}\right)$ & $1,2^{\mathrm{d}}$ & $86,8^{\mathrm{a}}$ \\
EPF $5\left(60^{\circ} \mathrm{C}, 1 \mathrm{~h}\right)$ & $1,8^{\mathrm{b}}$ & $75,5^{\mathrm{c}}$ \\
EPF $6\left(60^{\circ} \mathrm{C}, 5 \mathrm{~h}\right)$ & $1,7^{\mathrm{c}}$ & $81,2^{\mathrm{b}}$ \\
\hline
\end{tabular}

$\mathrm{EPF}=$ Extrato protéico do fubá de milho. Os resultados representam médias de triplicatas. Médias indicadas por letras iguais não diferem entre si a $5 \%$ de significância quanto ao rendimento da extração, em matéria seca.

A extração incompleta das proteínas, provavelmente se deve à interferência da matriz, devido às interações com outros constituintes da amostra, tais como lípides e carboidratos [13]. No caso de isolados protéicos do arroz, o amido é o maior contaminante e a sua elevada solubilidade na água parece ser responsável pelo baixo rendimento protéico [1].

Não foram encontrados na literatura relatos referentes à extração enzimática das proteínas do milho ou de seus derivados. Assim, considerando que alguns autores empregaram este método para a extração protéica de outros alimentos, os dados aqui obtidos foram comparados com os destes autores. Dessa forma, considerando a média dos três melhores resultados $(85,3 \%)$, verifica-se que este valor aproxima-se dos encontrados por FISCHER et al. [13], que obtiveram um rendimento de $89-94 \%$ das proteínas da farinha de soja, utilizando uma combinação de proteases (alcalase e flavourzima). EUBER, PUSKI \& HARTMAN [8], utilizando a pancreatina como enzima no processo de extração de proteínas do arroz, obtiveram $75 \%$ de rendimento para as melhores condições testadas, valor este semelhante à amostra EPF 5 no presente trabalho. TANG, HETTIARACHCHY \& SHELLHAMMER [30] alcançaram rendimentos de extração de 56,2 a $66,6 \%$, utilizando processamentos físicos (ultrasom, ultra-turrax, alta pressão) e enzimáticos na extração da proteína do farelo de arroz. Estes resultados são inferiores aos obtidos neste trabalho.

Com relação ao teor de proteínas do resíduo, observa-se, na Tabela 4 , que variou de 1,2 a $2,3 \%$, sendo menos elevado para extrações efetuadas a $55^{\circ} \mathrm{C}$, por $5 \mathrm{~h}(\mathrm{EPF} 2), 15 \mathrm{~h}$ (EPF 3) e 24 h (EPF 4), para as quais não foram observadas diferenças significativas. WANG \& WANG [32], utilizando uma protease neutra (Bacillus subtilis) para a obtenção do amido de arroz, por meio da extração enzimática das proteínas, obtiveram resultados inferiores, tendo o teor protéico nos resíduos variado de 0,53 a $0,88 \%$.

Em trabalho semelhante aos destes autores, AGBOOLA, NG \& MILLS [1], encontraram apenas 0,15\% de proteínas no 
resíduo do arroz, o que corresponde a um melhor resultado do que o de WANG \& WANG [32] e o do atual estudo. Por outro lado, FISCHER et al. [13] relataram um teor elevado de proteína (15-20\%) no resíduo obtido da extração enzimática da farinha de soja.

\subsection{1 - Efeito da temperatura}

Para comparar o efeito da temperatura no rendimento da extração das proteínas, deve-se comparar EPF 1 com EPF 5 $\left(55^{\circ} \mathrm{C}\right.$ e $\left.60^{\circ} \mathrm{C}\right)$ e EPF 2 com EPF $6\left(55^{\circ} \mathrm{C}\right.$ e $\left.60{ }^{\circ} \mathrm{C}\right)$. Pode-se observar, na Figura 1, que a temperatura afetou o rendimento da extração, uma vez que houve diferença significativa entre os resultados. O efeito desejável, associando a diminuição da temperatura com o aumento do rendimento, relacionado à redução de custos do processo, foi observado no caso de se utilizar o tempo de 5 h de extração (EPF 6 com EPF 2). $\mathrm{O}$ fato do rendimento de extração ter sido inferior a $60{ }^{\circ} \mathrm{C}$ pode estar relacionado à proximidade da temperatura de gelatinização do amido de fubá de milho, que está na faixa de $62{ }^{\circ} \mathrm{C}-72{ }^{\circ} \mathrm{C}[4]$. Neste processo, parte das proteínas ligadas às moléculas de amido, poderia estar inacessível à ação da enzima. Quando se utilizou $1 \mathrm{~h}$ de extração, este efeito não foi observado ( $\mathrm{EPF} 1,55^{\circ} \mathrm{C} \operatorname{com} \mathrm{EPF} 5,60{ }^{\circ} \mathrm{C}$ ), o que poderia estar associado à ocorrência de menor gelatinização do amido devido ao tempo de reação ter sido insuficiente para que este processo ocorresse.

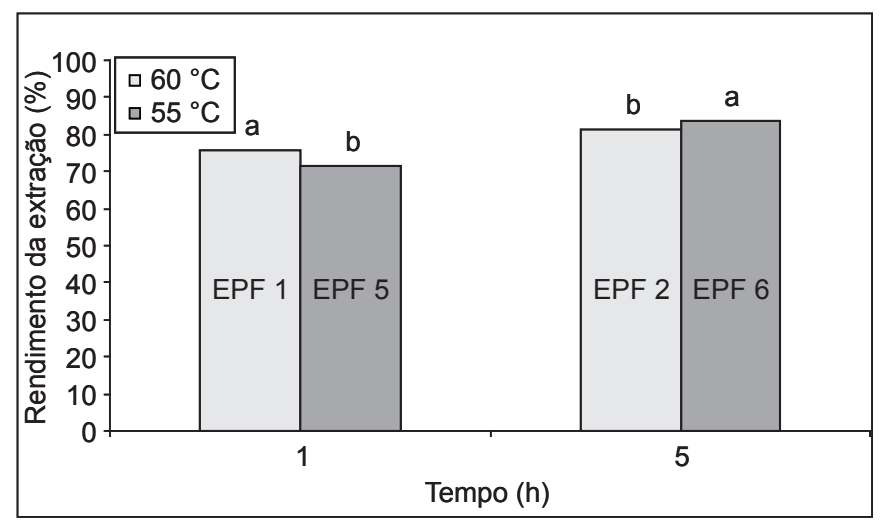

FIGURA 1 - Efeito da temperatura no rendimento da extração enzimática.

Tal como o observado no atual estudo para $5 \mathrm{~h}$ de reação, EUBER, PUSKI \& HARTMAN [8], empregando a pancreatina para a extração das proteínas do arroz, obtiveram um aumento do rendimento com a queda de temperatura de $60{ }^{\circ} \mathrm{C}$ para $55^{\circ} \mathrm{C}$.

\subsection{2 - Efeito do tempo}

Para avaliar o efeito do tempo no rendimento de extração das proteínas (Figura 2), são comparados entre si EPF 1 ( 1 h), EPF 2 (5 h), EPF 3 ( 15 h) e EPF 4 (24 h). Assim, ao se passar de $1 \mathrm{~h}$ (EPF 1) para $5 \mathrm{~h}$ (EPF 2), houve um aumento significativo no rendimento de extração. Este resultado está de acordo com o esperado teoricamente, ou seja, o aumento no tempo de ação da enzima é importante para se elevar o rendimento de extração, pois produz uma hidrólise mais acentuada da molécula protéica, com a formação de peptídeos de cadeias mais curtas que são mais solúveis [13]. Por outro lado, passando-se de 5 h (EPF 2) para $15 \mathrm{~h}$ (EPF 3), assim como de $15 \mathrm{~h}$ (EPF 3) para $24 \mathrm{~h}$ (EPF 4), não foram observadas diferenças significativas nos valores encontrados.

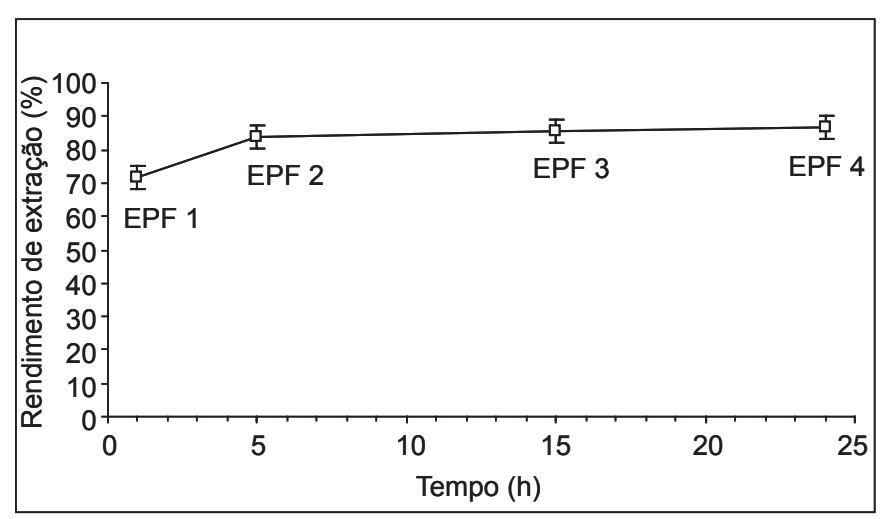

FIGURA 2 - Efeito do tempo no rendimento da extração enzimática.

Estes resultados indicam, ainda, que considerando os riscos de contaminação e os custos para a aplicação do processo em larga escala, a condição mais vantajosa é representada pela extração por $5 \mathrm{~h}$ a $55^{\circ} \mathrm{C}(\mathrm{EPF} 2)$.

EUBER, PUSKI \& HARTMAN [8], empregando a pancreatina para a extração protéica do arroz, observaram que a diminuição do tempo de $5 \mathrm{~h}$ para $1 \mathrm{~h}$ teve o mesmo efeito negativo do presente trabalho, tendo reduzido o rendimento de extração de $76,5 \%$ para $69,1 \%$.

Com interesse em obter o amido do arroz, WANG \& WANG [32] empregaram uma protease neutra do Bacillus subtilis para a extração das proteínas, tendo relatado que a redução do tempo de hidrólise de $5 \mathrm{~h}$ para $1 \mathrm{~h}$ levou, desvantajosamente, a um aumento do teor protéico do resíduo $(0,55$ para $0,88 \%)$. Este resultado está de acordo com o presente trabalho a $55{ }^{\circ} \mathrm{C}$ (EPF 2 e EPF 1), uma vez que ao passar de $5 \mathrm{~h}$ para $1 \mathrm{~h}$ obteve-se uma elevação do teor protéico do resíduo.

\section{4 - Extração química x extração enzimática}

Comparando entre si os melhores resultados obtidos por estes dois métodos de extração, observa-se, primeiramente, que o enzimático apresentou rendimento inferior $(83,5 \%)$ ao alcalino-alcoólico seqüencial (88,2\%). Entretanto, o emprego de enzimas, ao invés de solventes, reduz demasiadamente os riscos para a saúde, uma vez que, o $\mathrm{pH}$ fortemente alcalino pode alterar as propriedades nutricionais e funcionais das proteínas, aumentar as chances de racemização dos aminoácidos, provocar a destruição dos aminoácidos e formar 
novos compostos [27]. Outra vantagem do método enzimático relaciona-se a uma maior digestibilidade protéica, uma vez que a hidrólise dá origem a oligopeptídeos que são absorvidos mais rápida e completamente que as proteínas intactas [8, $17,28,34]$. Ressalta-se ainda que, ao contrário da extração química, no método enzimático não houve necessidade de se fazer a neutralização do resíduo e do sobrenadante, uma vez que o pH final da extração situava-se em torno de 7,0. Isto se deve à hidrólise enzimática de proteínas, na qual ocorre a quebra das ligações peptídicas e, conseqüentemente, a liberação de grupamentos terminais dos peptídeos. Em soluções aquosas, estes grupos se encontram na forma ionizável $\left(\mathrm{COO}^{-}+\mathrm{H}^{+}\right)$, e os prótons livres neutralizam a alcalinidade do meio [16, 22].

\section{4 - CONCLUSÃO}

O método alcalino-alcoólico seqüencial foi o mais eficiente, dentre os métodos químicos testados para extração das proteínas do fubá de milho, tendo alcançado 88,2\% de rendimento. No método enzimático, para alguns casos $(1 \mathrm{~h}$ para $5 \mathrm{~h}$ ) o tempo e a temperatura empregados influenciaram no rendimento da extração protéica do fubá de milho, sendo que a condição de $5 \mathrm{~h}$ a $55{ }^{\circ} \mathrm{C}$ foi a mais vantajosa do ponto de vista econômico, tendo atingido um rendimento de $83,8 \%$.

\section{5 - REFERÊNCIAS BIBLIOGRÁFICAS}

[1] AGBOOLA, S.; NG, D.; MILLS, D. Characterization and functional properties of Australian rice protein isolates. J. Cereal Sci., Pennsylvania, v. 41, n. 3, p. 283-290, may, 2005.

[2] ASSOCIATION OF OFFICIAL ANALYTICAL CHEMISTS - AOAC. Official methods of analysis of AOAC international, 16. ed. Arlington: AOAC International, 1995. v. 2.

[3] BIZZOTTO, C. S. et al. Hidrolisados protéicos de arroz com baixo teor de fenilalanina, obtidos pela ação da corolase pp e uso do carvão ativado. Cienc. Agrotec., Lavras, v. 30, n. 2, p. 308-316, mar./abr. 2006.

[4] BOBBIO, F. O.; BOBBIO, P. A. Introdução à química de alimentos. 2. ed. São Paulo: Varela, 1992. 222p.

[5] CONNOR, M. A.; SAUNDERS, R. M.; KOHLER, G. O. Rice bran protein concentrates obtained by wet alkaline extraction. Cereal Chem., St. Paul, v. 53, n. 4, p. 488-496, jul./aug. 1976.

[6] DICKEY, L. C. et al. Zein batch extraction from dry-milled corn: cereal disintegration fluid shear. Cereal Chem., St. Paul, v. 75, n. 4, p. 443-448, jul./aug. 1998.

[7] DICKEY, L. C. et al. Estimating the cost of extracting cereal protein with ethanol. Ind. Crops Products, Kidlington, v. 10, n. 2, p. 137-143, sep. 1999.

[8] EUBER, J. R. et al. Evansville, IN. Method for making soluble rice protein concentrate and the product produced therefrom. United States Patent n. 4.990.344, feb. 5, 1991.

[9] EVERES, T. Maize - a versatile performer on the world stage. Disponível em: <http:/www.satake.co.uk/noflash. html >. Acesso em: 20 jan. 2006.
[10] FAGEER, A. S. M.; TINAY, A. H. E. Effect of genotype, malt pretreatment and cooking on in vitro protein digestibility and protein fractions of corn. Food Chem. London, v. 84, n. 4, p. 613-619, mar. 2004.

[11] FAO - FOOD AND AGRICULTURE ORGANIZATION - FAO Statistical Databases. Disponível em: <http://www. apps.fao.org/default.jsp>. Acesso em: 5 fev. 2006.

[12] FAO - FOOD AND AGRICULTURE ORGANIZATION. Maize in Human Nutrition. 1. ed. Rome: FAO, 1992. 168 p.

[13] FISCHER, M. et al. Enzymatic extractability of soybean meal proteins and carbohydrates: heat and humidity effects. J. Agric. Food Chem., Easton, v. 49, n. 9, p. 4463-4469, sep. 2001.

[14] FRANCO, G. Tabela de composição química dos alimentos. 9. ed. São Paulo: Atheneu, 1999. 307p.

[15] GONÇALVES, R. A. et al. Rendimento e composição química de cultivares de milho em moagem a seco e produção de grifts. Cienc. Agrotec., Lavras, v. 27, n. 3, p. 643-650, maio/jun. 2003.

[16] GUADIX, A., et al. Procesos tecnológicos y métodos de control en la hidrólisis de proteínas. Ars Pharm. Granada, v. 41, n. 1, p. 79-89, jan./mar. 2000.

[17] GRIMBLE, G. K. et al. Effect of peptide chain length on amino acids and nitrogen absorption from two lactoalbumin hydrolysates in the normal human jejunum. Clin. Sci., London, v. 71, n. 1, p. 65-69, jan.1986.

[18] HOJILla-EVANGELISTA, M. P.; JOHNSON, L. A.; MYERS, D. J. Sequencial extraction processing of flacked whole corn: alternative corn fractionation technology for ethanol production. Cereal Chem., St. Paul, v. 69, n. 6, p. 643-647, nov./dec. 1992.

[19] KAMPEN, W. H. Charlotte, NC. Recovery of protein isolate and/or starch from cereal grains. United States Patentn. 5.410.021, apr. 25,1995.

[20] LANDRY, J. Comparison of extraction methods for evaluating zein content of maize grain. Cereal Chem. St. Paul, v. 74, n. 2, p. 188-189, mar./apr. 1997.

[21] LANDRY, J.; MOUREAUX, T. Heterogeneity of the glutelins of the grain corn: Selective extraction and composition in amino acids of the three isolated fractions. Bull. Soc. Chem. Biol., Princeton, v. 52, p. 1021-1037, 1970.

[22] LEHNinger, A. L.; NELSON, D. L.; COX, M. M. Princípios de bioquímica. 2. ed. São Paulo: Sarvier, 1995.

[23] NEWMANN, P. E.; WALL, J. S. Chemical and physical properties of proteins in wet-milled corn gluten. Cereal Chem., St. Paul, v. 61, n. 3, p. 353-356, may/ jun. 1984 .

[24] NIELSEN, S. S. Food analysis. 2. ed. Gaithersburg: Aspen Publisher, 1998. 630 p.

[25] PAULIS, J. W.; WALL, J. S. Fractionation and characterization of alcohol-soluble reduced corn endosperm glutelin proteins. Cereal Chem., St. Paul, v. 54, n. 6, p. 1223-1228, nov./dec. 1977.

[26] PIMENTEL-GOMES, F. Curso de estatística experimental. 14. ed. Piracicaba: Livraria Nobel S.A., 2000. $477 \mathrm{p}$.

[27] SGARBIERI, V. C. Proteínas em alimentos protéicos; propriedades, degradações, modificações. 1. ed. São Paulo: Varela, 1996. 517 p. 
[28] SHIMAMURA, S. et al. Tokyo, J. P. Peptide mixture and products thereof. United States Patent n. 5952193, sep. 14, 1999.

[29] SHUKLA, R.; CHERYAN, M.; DE VOR, R. E. Solvent extraction of zein from dry-milled corn. Cereal Chem., St. Paul, v. 77, n. 6, p. 724-730, nov./dec. 2000.

[30] TANG, S.; HETTIARACHCHY, S.; SHELLHAMMER, T. H. Protein extraction from heat-stabilized defatted rice bran.1. Physical processing and enzyme treatments. J. Agric. Food Chem., Easton, v. 50, n. 25, p. 7444-7448, dec. 2002.

[31] USP (Universidade do Estado de São Paulo). Tabela Brasileira de Composição de Alimentos, 2005. Disponível em <http://www.fcf.usp.br/tabela/> . Acesso em 15 out. 2005 .
[32] WANG, L.; WANG, Y. J. Rice starch isolation by neutral protease and high-intensity ultrasound. J. Cereal Sci., Pennsylvania, v. 39, n. 2, p. 291-296, mar. 2004.

[33] YOUSIF, N. E.; TINAY, A. H. E. 1. Effect of fermentation on protein fractions and in vitro protein digestibility of maize. Food Chem., London, v. 70, n. 2, p. 181-184, ago. 2000.

[34] ZIEGLER, F. et al. Efficiency of enteral nitrogen support in surgical patients: small peptides and non-degraded proteins. Gut, London, v. 31, n. 11, p. 1277-1283, nov. 1990.

\section{6 - AGRADECIMENTOS}

Os autores agradecem à Fapemig, à CAPES e ao CNPq pelo apoio financeiro a este trabalho, nas formas de auxílio à pesquisa e bolsas de Mestrado e Iniciação Científica. 